\title{
CONTROLE PID de ToRque PARA MOtORES A COMBUStão INTERNA
}

Marcos Henrique C. Silva ${ }^{1}$, Armando Antônio M. Laganá ${ }^{1,2}$, Sérgio I. Ferreira ${ }^{3}$, Marco I. Naufal ${ }^{3}$, Bruno S. Pereira ${ }^{1}$, Demerson Moscardini ${ }^{1,2}$, Lucas M. de Novaes ${ }^{1}$

\author{
${ }^{1}$ Escola Politécnica da Universidade de São Paulo \\ ${ }^{2}$ Fatec Santo André \\ ${ }^{3}$ Instituto de Pesquisas Tecnológicas do Estado de São Paulo \\ E-mails:marcoshencarsil@gmail.com, armandolagana@terra.com.br, ferreira@ipt.br, \\ mnaufal@ipt.br, bruno6_spp@hotmail.com,demersondonoc@hotmail.com, \\ lucassp14@hotmail.com
}

\section{RESUMO}

Unidades de controle vêm desempenhando um importante papel no funcionamento de motores modernos, aumentando o consumo, a performance e melhorando as emissões de poluentes. Neste artigo, o controle de torque é abordado. Será usado um sensor virtual de torque, para obter a variável medida torque, a ser usada como entrada do modelo de controle. Será exposto o uso de controlador PID para efetuar o controle de torque, assim como as calibrações e ajustes necessários neste controlador, como filtros e saturações. Haverá análises sobre os sinais de atuação, de forma a avaliar a compatibilidade do sinal com a capacidade de resposta dos atuadores. O controlador projetado atua sobre a válvula borboleta, o bico injetor e a bobina de ignição, o que o torna apenas adequado para situação de não detonação com alta demanda de energia ou aceleração.

Palavras-chave: controle PID, motores a combustão interna, controle de torque, modelo de torque 


\section{INTRODUÇÃO}

Exigências legislativas e de mercado, concernentes a aspectos como consumo e emissões, proporcionaram transformações na tecnologia automotiva, demandando o emprego de novas técnicas de engenharia. Teve-se o grande aumento de funções e operações no motor, e no veículo como um todo, que passaram a ter, tanto na estrutura quanto no controle, dispositivos de elétrica e eletrônica.

No motor de combustão interna operando em ciclo Otto, a tomada de ar, a injeção de combustível e o instante de ignição são controlados, atualmente, por uma unidade de controle eletrônica (ECU - electronic control unit). A tomada de ar, controlada pela válvula borboleta, está relacionada com a carga que poderá ser gerada pelo motor, entendendo carga aqui como o torque efetivo gerado. Para cada quantidade de massa de ar admitida por ciclo por cilindro, haverá uma faixa de torque efetivo que poderá ser produzida. A injeção de combustível, controlada pelo bico injetor, está relacionada com a energia química admitida pelo motor. Haverá uma vinculação necessária entre a quantidade de ar e de combustível injetados, devido, entre outros motivos, aos componentes usados para o tratamento das emissões, como catalisadores. O instante de ignição, controlado pela bobina de ignição, está relacionado ao início da combustão, que impacta diretamente na eficiência indicada e nas pressões e temperaturas internas ao cilindro do motor [1].

O controle do início da combustão, realizado através do comando do ângulo de ignição, deve buscar aproximar o ângulo de ignição do instante de MBT (maximum brake torque timing). Neste instante, a eficiência indicada é otimizada com relação ao ângulo de ignição. Devido a este motivo, o instante do MBT pode ser nomeado de ângulo ótimo de ignição [2]. Porém, nem sempre é possível a ignição operar no ângulo ótimo devido à detonação. Quando o sensor de detonação a detectar, o ângulo de ignição deve ser distanciado do instante ótimo, pois desta forma as pressões e as temperaturas internas ao cilindro do motor são amenizadas, diminuindo-se a probabilidade de ocorrência da detonação. 
O controle da injeção de combustível, realizado através do bico injetor, procura proporcionar com que o cilindro do motor admita uma quantidade adequada de combustível. Adota-se uma referência da razão ar-combustível injetada e se projeta um controlador que siga esta referência, que pode ser diversa conforme diferentes componentes de tratamento de emissão são usados, como TWC, que opera melhor com mistura média estequiométrica, e LNT, que opera melhor com mistura média pobre [3].

O controle da tomada de ar, realizado através da válvula borboleta, é tradicionalmente vinculado à demanda do pedal realizada pelo motorista. Como, conforme dito, a tomada de ar define a faixa de torque efetivo que pode ser gerada, conforme maior a demanda de energia do motorista, através do pedal, maior deve ser a tomada de ar. Deve-se, neste caso, aumentar o ângulo de abertura da válvula borboleta.

Em uma operação normal de um motor, sem grande demanda de torque pelo motorista e sem frenagem, em uma ECU tradicional, o ângulo de ignição fica sujeito ao controle de detonação, o tempo de injeção ao controle de lambda e a abertura da válvula borboleta à demanda do pedal. No entanto, em instantes de aceleração e de grande demanda de torque, para aumentar a performance do motor, pode-se habilitar um controlador de torque que comande os três atuadores: bico injetor, bobina de ignição e válvula borboleta. O comando de todos os três pelo controlador de torque pode ser mantido enquanto não há detonação e enquanto as condições (aceleração ou grande demanda de torque) se mantiverem.

Neste artigo, será proposto um controlador PID de torque. Devido a não linearidade do motor, haverá implementação de gain-scheduling nos termos proporcional e integrativo, adaptando-os conforme são variados a referência de torque e a rotação do motor. Esse controlador de torque multivariável foi projetado em ambiente Simulink, com o uso do modelo de torque do motor EA 111 VHT 1.6 litro. Primeiro, será exposto o modelo de torque empregado. A seguir, será apresentado o controlador projetado, com as devidas discussões dos resultados experimentais. 


\section{MODELO DE TORQUE}

Devido a se buscar um modelo de torque visando o controle da ECU, as entradas deste modelo devem justamente ser os sinais de atuação dos atuadores envolvidos (bico injetor, bobina de ignição e válvula borboleta) e a saída será o torque. Como a frota comercial de veículos não costuma dispor de um sensor de torque, como o sensor de pressão interna ao cilindro do motor, devido a seu alto custo, na ECU deverá ser implementado um sensor virtual de torque, fazendo-se, para tanto, uso do modelo de torque desenvolvido.

O modelo de torque segue, conforme equações (1) e (2) [4].

$$
\begin{gathered}
T_{e}=e_{i}(.) \cdot m_{\varphi} \cdot H_{l}-\frac{V_{d}}{4 \cdot \pi} \cdot\left[p_{\text {meog }}(0)+p_{\text {meof }}(.)\right] \\
e_{i}(.)=e_{\omega_{e}}\left(\omega_{e}\right) \cdot e_{\lambda}(\lambda) \cdot e_{\zeta}(\zeta) \cdot e_{e g r}\left(x_{e g r}\right)+p_{m e 0 g}(0) \cdot K \\
\cdot \frac{\lambda \cdot \sigma_{0} \cdot V_{d}}{H_{l} \cdot m_{\beta, \max }\left(\omega_{e}\right)}
\end{gathered}
$$

Em que:

$e_{i}($.$) : Eficiência indicada;$

$\omega_{e}$ : Rotação do motor;

$e_{\omega_{e}}\left(\omega_{e}, m_{\varphi}\right)$ : Fator da eficiência indicada dependente da rotação do motor e da massa de combustível admitida;

$e_{\lambda}(\lambda)$ : Fator da eficiência indicada dependente da relação equivalente ar/combustível; $\zeta$ : Ângulo de ignição;

$e_{\zeta}(\zeta)$ : Fator da eficiência indicada dependente do ângulo de ignição;

$x_{e g r}$ : Taxa de recirculação de gases (pode ser mássica ou molar);

$e_{e g r}\left(x_{e g r}\right)$ : Fator da eficiência indicada dependente da taxa de recirculação de gases;

$p_{m e 0 g}(0)$ : Perdas devido ao atrito do fluxo gasoso no cilindro e no sistema de exaustão;

$K$ : Constante determinada experimentalmente; 
$\lambda$ : Relação equivalente ar-combustível;

$\sigma_{0}$ : Relação estequiométrica ar-combustível;

$V_{d}$ : Volume de deslocamento;

$H_{l}$ : Poder calorífico inferior da mistura de combustível utilizada;

$m_{\beta}$ : Valor mássico da mistura de ar com gases queimados recirculados admitida pelo cilindro em um ciclo determinado;

$m_{\beta, \max }\left(\omega_{e}\right)$ : Máximo valor de $m_{\beta}$ possível de se obter em determinada rotação do motor;

$T_{e}$ : Valor médio de torque efetivo produzido em um ciclo determinado;

$m_{\varphi}$ : Valor mássico da mistura de combustível admitida pelo cilindro em um ciclo determinado;

$p_{m e 0 f}($.$) : Engloba as perdas devido às fricções das partes móveis mecânicas do motor$ e as perdas devido ao funcionamento de dispositivos auxiliares, como as bombas de água e óleo, o ar-condicionado, a ventoinha, dentre outros.

O modelo de torque, conforme as equações, é a soma de dois termos. No primeiro, dependente da energia química admitida (massa de combustível admitida pelo cilindro), estão englobados os fenômenos que afetam a eficiência indicada. No segundo termo estão as perdas de torque não dependentes da massa de combustível admitida, que seria a soma do torque perdido devido aos atritos do fluxo gasoso e das partes móveis do motor com o torque perdido devido ao funcionamento de dispositivos auxiliares. O torque perdido devido ao atrito do fluxo gasoso é numericamente igual ao torque perdido devido ao bombeamento gasoso em condição de zero carga. $O$ torque perdido devido ao atrito das partes móveis pode ser modelado em função da temperatura do óleo e da rotação do motor como uma curva tridimensional, obtida através do motor operando em condição motorizada. Esta estratégia foi a usada nesta pesquisa. Outras possibilidades incluem o uso da curva de Williams [5] ou o modelo de Shayler [6].

A eficiência indicada pode ser decomposta, conforme equação (2), em uma série de fatores. Nesta decomposição, supõe-se que a influência que os gases recirculados, que o instante de ignição e que a relação ar-combustível exercem na eficiência indicada são independentes entre si. Portanto, para cada uma destas 
grandezas haverá um fator correspondente. $O$ fator $e_{\omega_{e}}$ se refere à eficiência indicada nas condições ótimas de ângulo de ignição, razão ar-combustível e recirculação de gases [5]. Nesta pesquisa, modelou-se $e_{\omega_{e}}$ em função da rotação do motor e da massa de combustível admitida por ciclo como uma curva tridimensional.

O segundo termo da equação (2) está relacionado à diminuição das perdas por bombeamento gasoso conforme se aumenta a carga. Logo, haverá um aumento de eficiência indicada considerando este aspecto [2].

Para poder se executar o modelo de torque, é necessário modelar, também, a tomada de ar e de combustível, pois há vários fenômenos que ocorrem com o ar e com o combustível injetado até formarem a mistura a ser queimada. A tomada de ar é controlada pela válvula borboleta, que interfere no fluxo do duto de ar. $\mathrm{O}$ ar, a seguir, sofre a dinâmica de preenchimento no coletor de admissão. O combustível injetado, ao ser admitido, deve antes se vaporizar. O fluxo de saída do coletor de admissão mistura-se com o combustível injetado formando a mistura ar-combustível a ser admitida. Na admissão, esta mistura sofre a dinâmica do back-flow e dos gases residuais. Como o motor não é uma bomba de ar ideal, a admissão também sofrerá limitações relacionadas à eficiência volumétrica. Após todos estes processos, tem-se, por fim, a mistura a ser queimada [7-9].

\section{MODELO DO CONTROLADOR}

O controlador de torque adotado é um PID adaptativo com gain-scheduling. Os termos proporcional e integral variam conforme a rotação e a referência de torque. Estas modificações foram necessárias devido a não linearidade do motor. O sinal a ser enviado para cada atuador tem, também, um ganho próprio. A lei de controle segue conforme equação (3) abaixo:

$$
u=K \cdot\left(k_{p} \cdot e+k_{i} \cdot \int e \cdot d t+k_{d} \cdot \frac{d e}{d t}\right)
$$


Ademais, são empregados saturadores em todos os sinais de atuação. No caso da válvula borboleta, para cada rotação, existe um ângulo de abertura mínimo, abaixo do qual o motor corre risco de morrer. Não há limite máximo para a abertura da válvula borboleta, podendo haver abertura de cem porcento em qualquer rotação. No caso do ângulo de ignição, adota-se sempre um mínimo de cinco graus antes do ponto morto superior, para se evitar que a combustão se inicie no ciclo de expansão. $O$ limite máximo do ângulo de ignição é o instante de MBT, o qual varia com a rotação e a pressão no coletor de admissão. No caso da quantidade de combustível injetada, ela deve obedecer aos limites de operação do motor, pois em uma mistura muito rica ou muito pobre ocorre misfire. No entanto, devido ao uso do PID não-linear conforme projetado, deve-se garantir que o ganho que relaciona o combustível injetado e o torque seja sempre positivo. Como o torque passa a decrescer com uma injeção excessiva, logo se deve adotar este limite na saturação. Portanto, no motor em estudo, deve-se levantar qual a relação ar-combustível que maximiza o torque e adotar o valor desta relação como um dos limites da saturação.

De forma a suavizar o sinal enviado aos atuadores, são empregados filtros de primeira ordem com constante de tempo 0.02 segundo. O não uso dos filtros podem gerar sinais bruscos não compatíveis com a capacidade de resposta dos atuadores. O diagrama em Simulink do sistema (modelo do motor + modelo do controlador) pode ser visto na figura 1.

\section{RESULTADOS EXPERIMENTAIS}

De forma a avaliar a performance do controlador projetado, serão realizadas simulações com diferentes cargas do motor. A rotação será mantida constante, emulando o ambiente de um laboratório com dinamômetro, o qual mantém a rotação fixa. Os sinais dos atuadores também serão analisados, de forma a discutir a viabilidade do projeto e a ação de controle. Nas figuras 2, 4 e 6, serão expostos os trackings da referência e nas figuras 3, 5 e 7 serão expostos os sinais de atuação. 


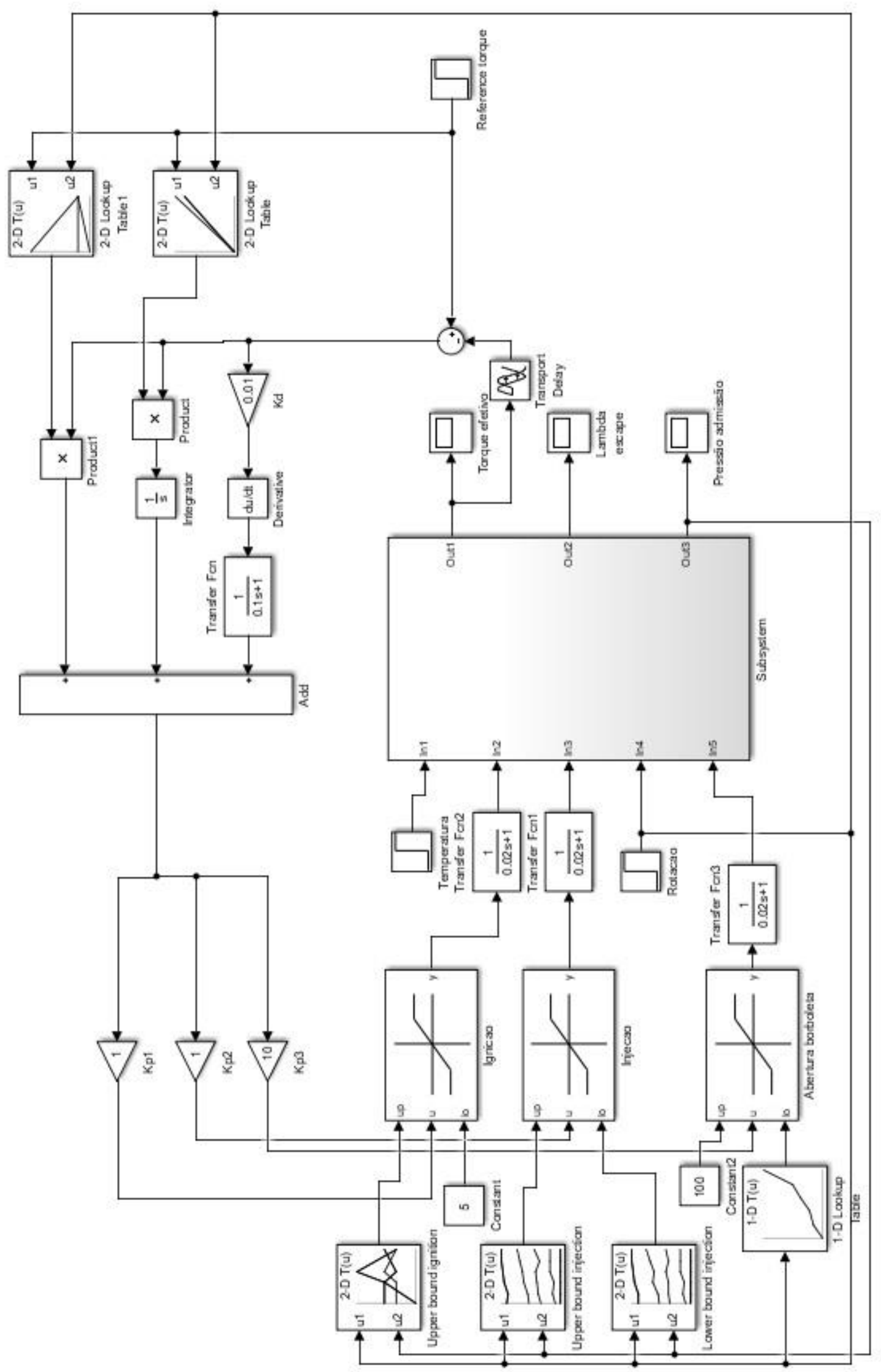

Figura 1: Diagrama em Simulink do sistema (planta + controlador) 


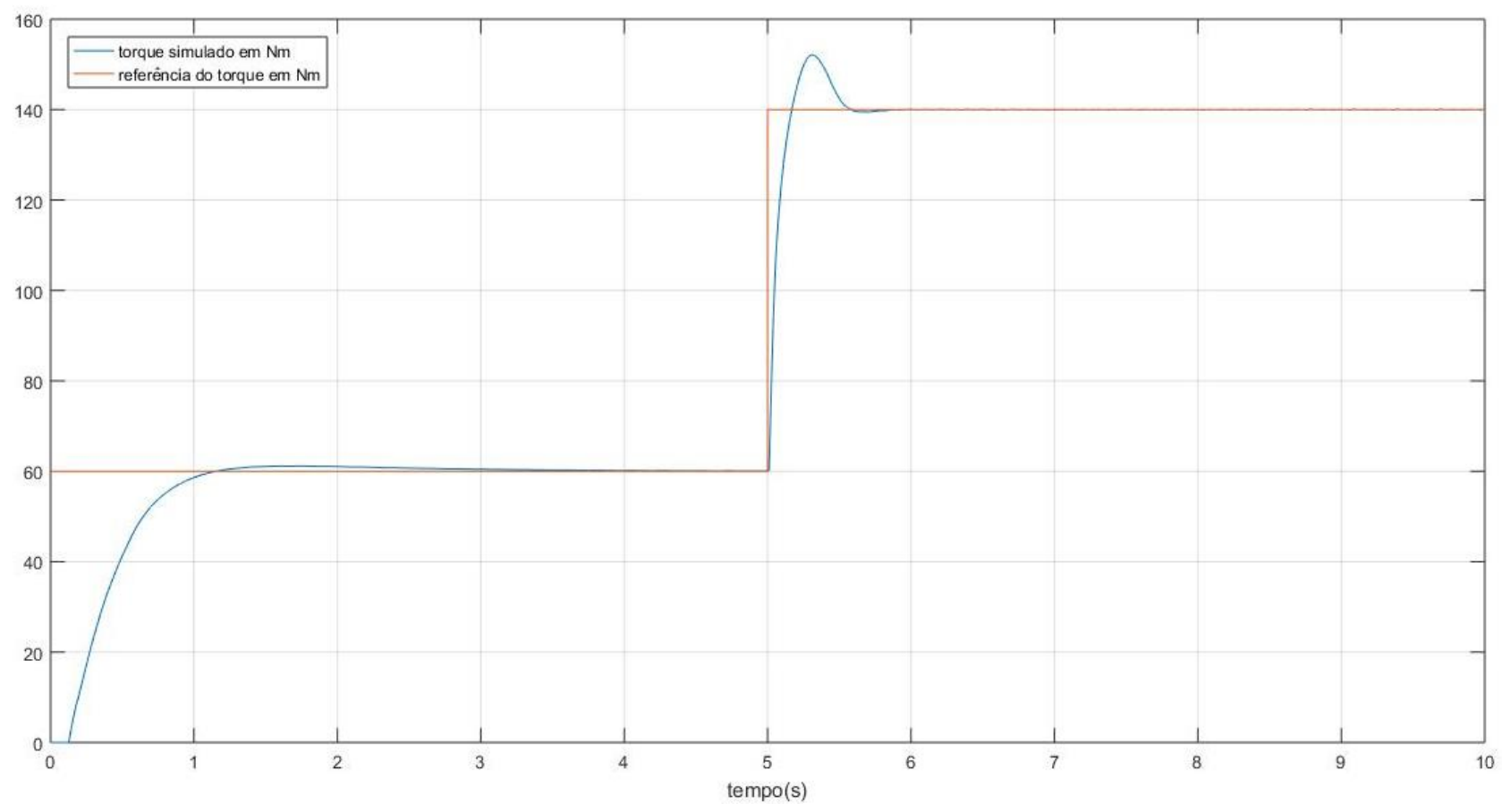

Figura 2: Tracking da referência para o motor a 1500RPM.

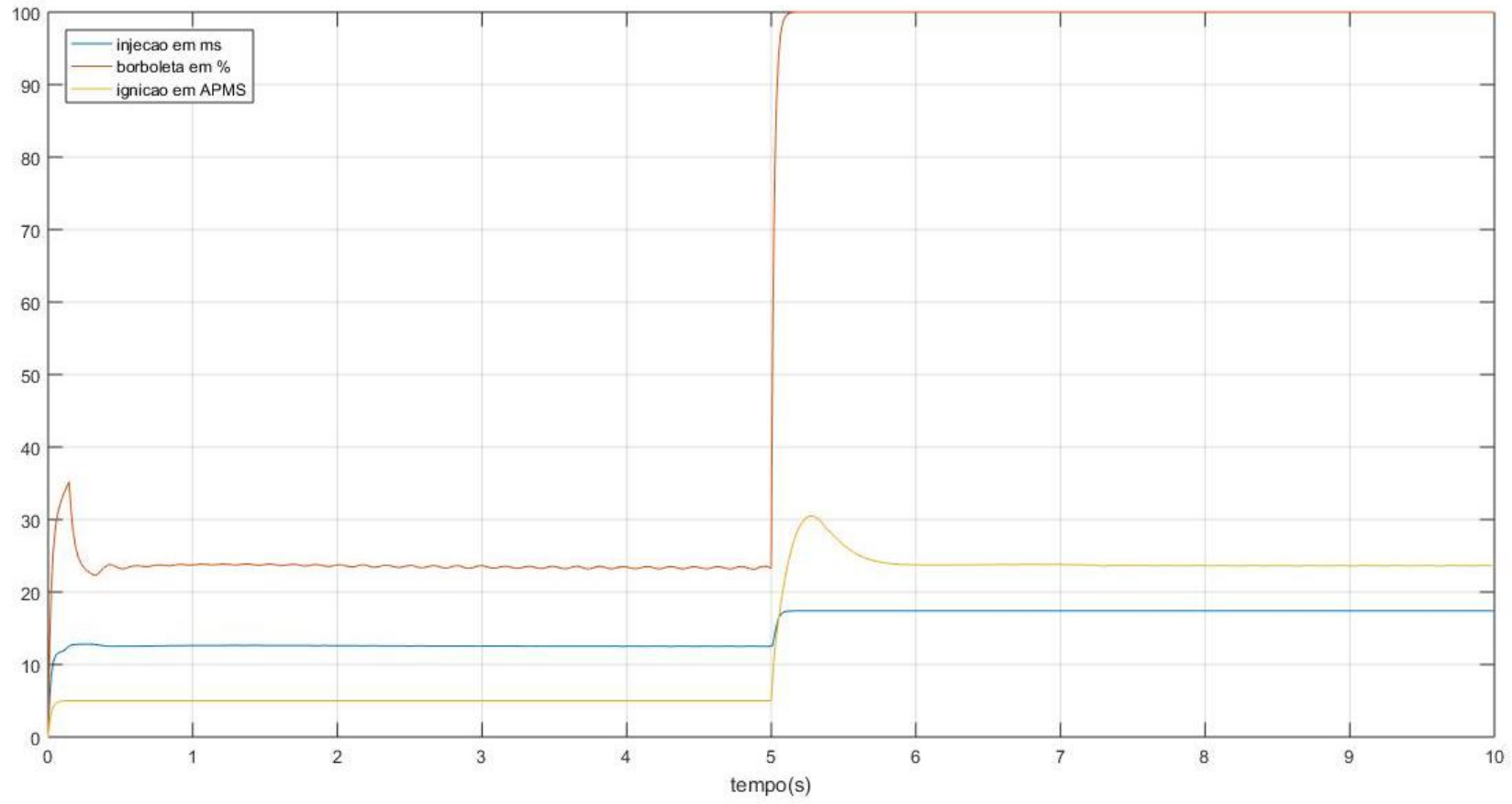

Figura 3: Sinais de atuação para o motor a 1500RPM. 


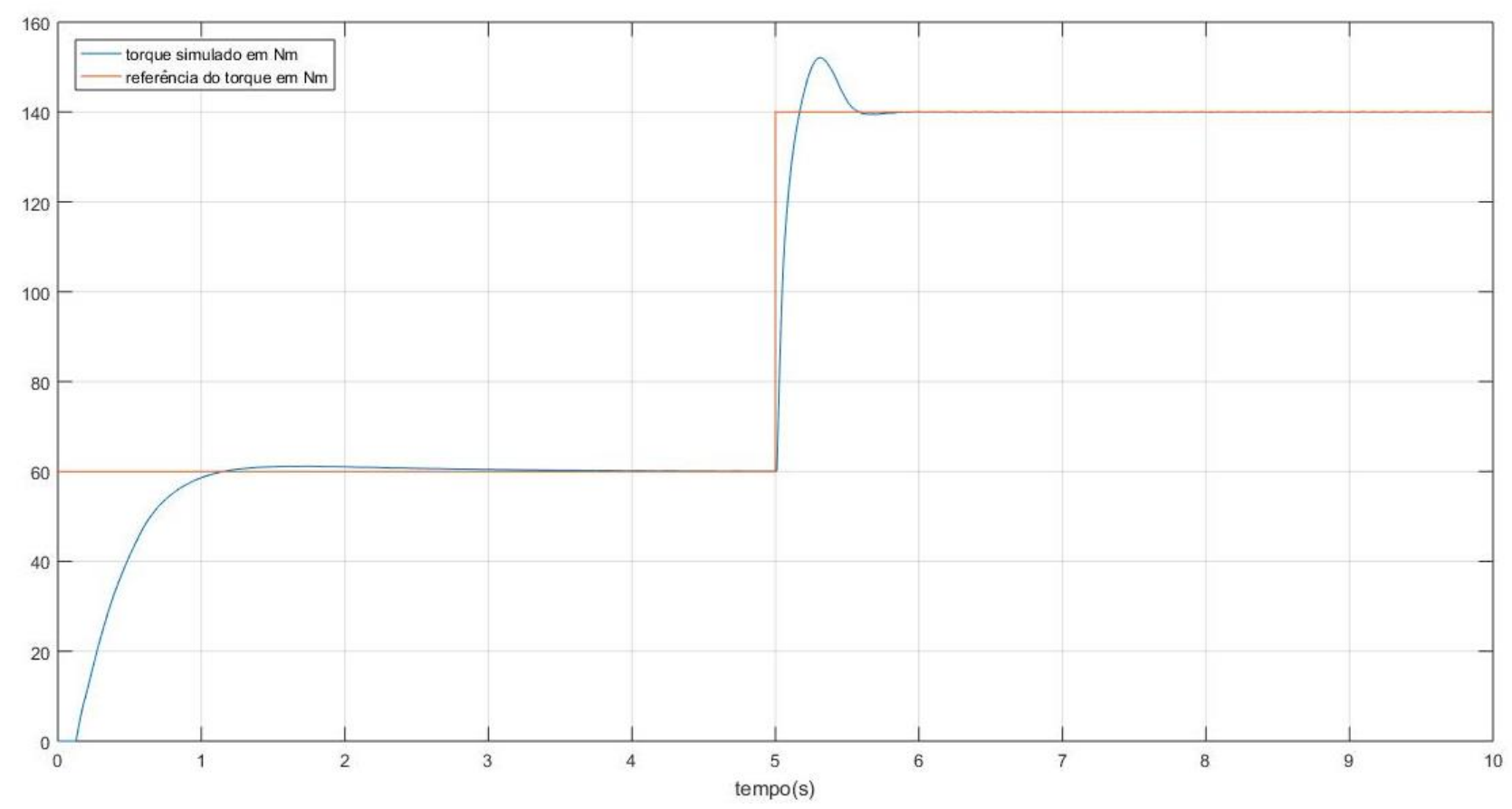

Figura 4: Tracking da referência para motor a 2750RPM.

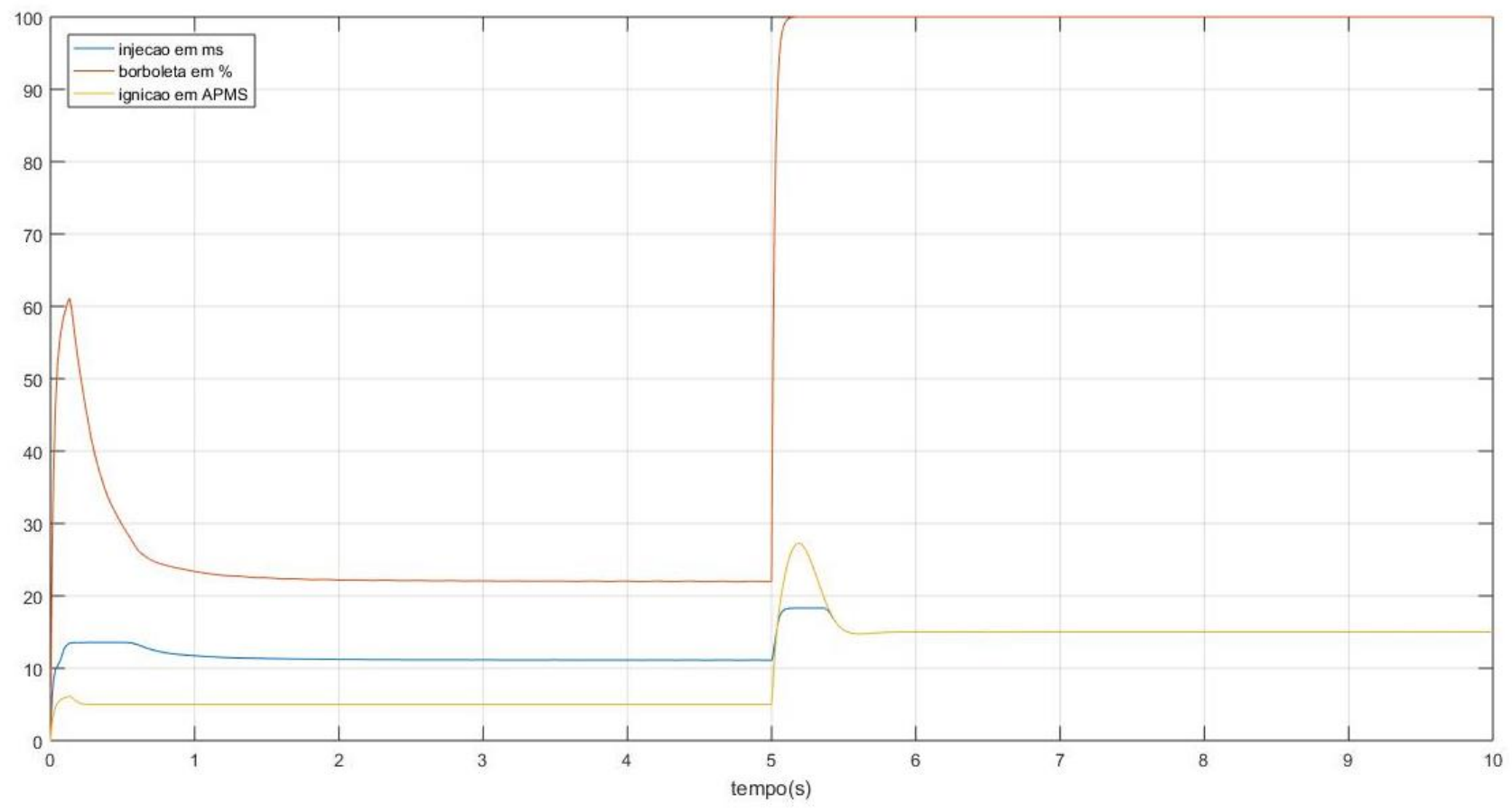

Figura 5: Sinais de atuação do motor a 2750RPM. 


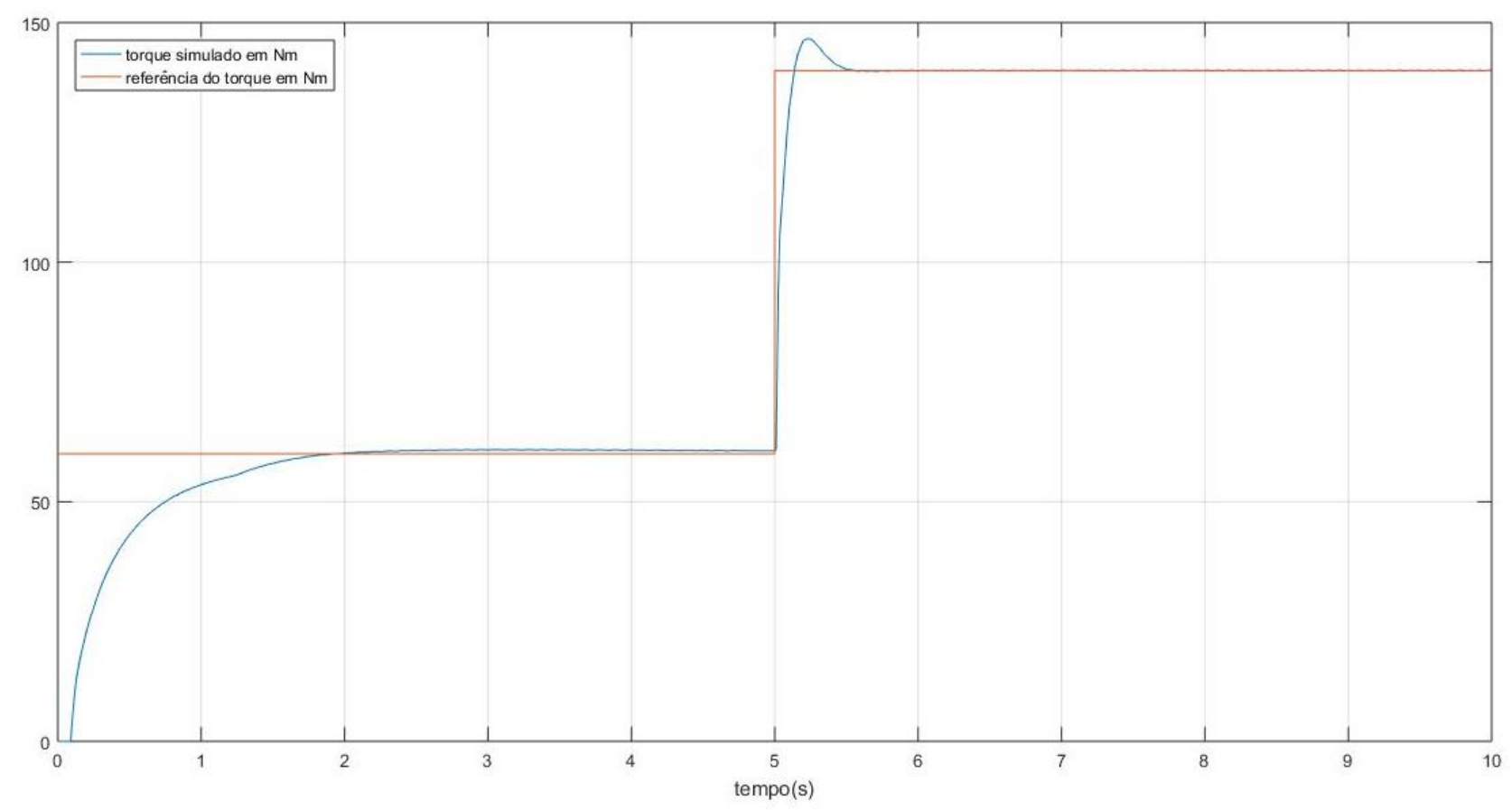

Figura 6: Tracking da referência do motor a 4000RPM.

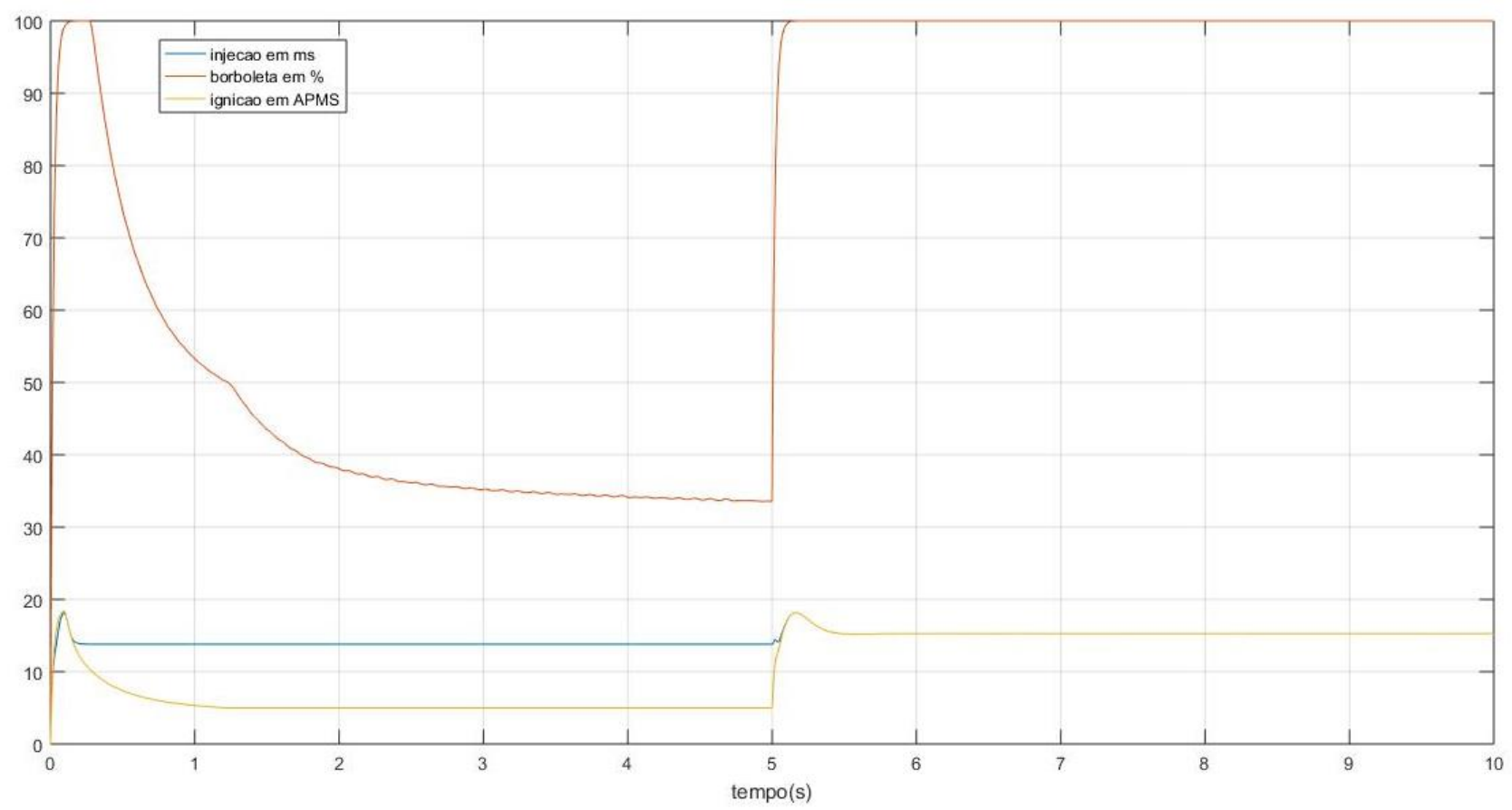

Figura 7: Sinais de atuação do motor a 4000RPM. 
Observa-se, dos resultados, que o tracking da referência ocorre mais rapidamente em altas cargas, independentemente da rotação. Observa-se um sobressinal, que foi em torno de $10 \mathrm{Nm}$ nas rotações 1500RPM e 2750RPM. A 4000RPM, há um sobressinal menor. Não houve erros de offset.

\section{CONCLUSÃO}

O artigo visou a projetar um controlador multivariável de torque, que controla a atuação do bico injetor, da bobina de ignição e da válvula borboleta. Como este controlador projetado comanda todos estes três atuadores, ele deve ser usado exclusivamente para situações de não detonação com alta demanda de energia ou aceleração.

Devido a elevada não linearidade do motor, fez-se uso de um controlador PID adaptativo com gain-scheduling, que apresentou melhor performance em altas cargas, o que favorece o uso deste controlador nas situações para as quais foi projetado. Saturações nos atuadores também foram incluídas no controlador, pois, devido a restrições relacionadas ao funcionamento do motor, os atuadores não podem operar em certas regiões.

\section{REFERÊNCIAS}

[1] MAGGIO, André V. O. Orientador: FILHO, João F. J. Simulação hardware-in-theloop de um motor de combustão flex. Dissertação de mestrado. Escola Politécnica da Universidade de São Paulo. 2019. No prelo.

[2] SILVA, M. H. Carvalho. Orientador: LAGANÁ, A. A. Maria. Modelagem de motores a combustão interna com tecnologia FLEX. Dissertação de mestrado. Escola Politécnica da Universidade de São Paulo. 2018.

[3] CHEN, Xuefei et al. Optimal air-to-fuel ratio tracking control with adaptive biofuel content estimation for LNT regeneration. IEEE Transactions on Control Systems Technology, v. 22, n. 2, p. 428-439, 2014. 
[4] SILVA, Marcos Henrique C.; LAGANÁ, Armando Antônio M.; "MODELAGEM DE TORQUE PARA MOTORES COM TECNOLOGIA FLEX", p. 767-779. In: SIMEA. São Paulo: Blucher, 2017. ISSN 2357-7592, DOI 10.5151/engpro-simea2017-57

[5] GUZZELLA, Lino; ONDER, Christopher. Introduction to modeling and control of internal combustion engine systems. Springer Science \& Business Media, 2009.

[6] CHALET, David et al. Nodal modelling for advanced thermal-management of internal combustion engine. Applied energy, v. 190, p. 99-113, 2017.

[7] SILVA, Marcos Henrique C.; LAGANÁ, Armando Antônio M.; "MODELAGEM DOS PERCURSOS DA MISTURA AR/COMBUSTÍVEL PARA UM MOTOR COM TECNOLOGIA FLEX", p. 345-357. In: SIMEA. São Paulo: Blucher, 2017. ISSN 23577592, DOI 10.5151/engpro-simea2017-26

[8] MOSKWA, John Joseph. Automotive engine modeling for real time control. 1988. Tese de Doutorado. Massachusetts Institute of Technology.

[9] LOCATELLI, Marzio A. Modeling and Compensation of the Fuel Path Dynamics of a Spark Ignited Engine. 2004. Tese de Doutorado. ETH Zurich. 